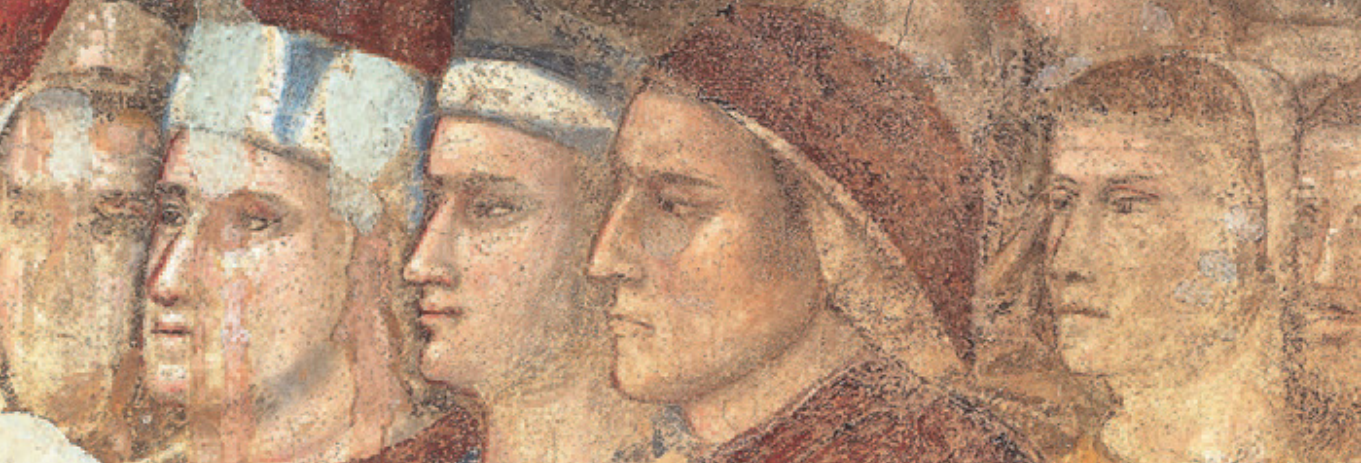

\section{El examen de Dante sobre la virtud de la fe}

\section{The examination of the virtue offaith for Dante}

\section{Resumen}

En el canto XXIV del Paraíso, Dante está llamado a contestar a una serie de preguntas sobre la virtud de la fe. El propósito de este artículo es - primero - mostrar cuál es la estructura lógica que subyace a la concepción de la creencia cristiana presente en dicho canto, - segundo - destacar que las respuestas del poeta están perfectamente en línea con las reflexiones de los escolásticos (en particular de Tomás de Aquino) El hecho de que Dante distinga entre la certeza absoluta de la fe sobrenatural y la duda de la investigación científica, puede verse como un rechazo de la doctrina argumentativa de la escolástica solo si se mal entiende el estatuto epistemológico que los teólogos medievales confieren a la ciencia de la fe.

\section{Palabras clave}

fe, Gracia, teología, escolástica, epistemología
Doctor en filosofía por la Universidad de Siena, ha sido investigador de la Fondazione Centro Studi Campostrini de Verona. Actualmente es docente a tiempo completo en la Universidad Católica San Pablo de Arequipa (Perú). Especialista en metafísica y filosofía de la religión, ha publicado numerosos artículos en revistas especializadas y tres monografías. Entre sus publicaciones científicas se encuentran las siguientes: "Suárez y la primera certeza del sentido común", en Philosophia, 80 (2020), pp. 91113; "The Alleged Violence of Christianity", en Philosophical News, 21 (2020).

\title{
ORCID
}

\begin{abstract}
In canto XXIV of Paradise, Dante is called to answer a series of questions about the virtue of faith. The purpose of this article is - first - to show what is the logical structure that underlies the conception of the Christian belief present in the canto in question, - second - to highlight that the poet's responses are perfectly in line with the reflections of the scholastics (particularly Thomas Aquinas). The fact that Dante distinguishes between the absolute certainty of supernatural faith and the doubt of scientific investigation, can be seen as a rejection of the argumentative doctrine of scholasticism only if the epistemological status that medieval theologians confer on the science of faith is misunderstood.
\end{abstract}

\section{Keywords}

faith, Grace, theology, scholasticism, epistemology

Recepción de artículo: 29-9-2021

Aceptación del artículo: 27-10-2021

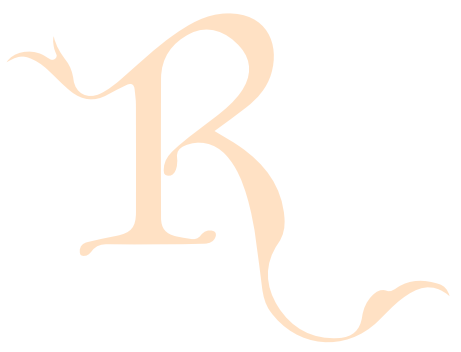


En el canto XXIV del Paraíso, San Pedro somete a Dante a un examen sobre la primera de las virtudes teologales. El poeta está llamado a contestar a una serie de preguntas para que explique qué es la fe y dé testimonio de cómo vivió en vida su creencia cristiana

El canto en cuestión se abre con la solemne oración de Beatriz a los bienaventurados, en particular a los Apóstoles, para que concedan a Dante algo de su sabiduría. Beatriz propone una metáfora: en el octavo cielo, el de las Estrellas Fijas, los bienaventurados, contemplando la gloria de Dios, son alimentados en 'la gran cena del bendito Cordero' 2 y beben 'de la fuente de la que mana lo que él piensa' ${ }^{3}$. De su mesa caen las migajas que pueden alimentar el enorme deseo de sabiduría que tiene el viator ${ }^{4}$. Se trata de una metáfora que recuerda el Evangelio de Juan ${ }^{5}$, en el cual se narra el episodio de la samaritana que fue reconocida por Jesucristo como una mujer de gran $\mathrm{fe}^{6}$. $\mathrm{Y}$ así como la samaritana sedienta de verdad pudo emprender un camino de fe a partir del encuentro y la relación con Jesús y su palabra, también Dante fue capaz de emprender un viaje que, pasando por la mesa de los bienaventurados, lo conducirá hacia su propia perfección y la verdad última de Dios ${ }^{7}$.

Los versos que relatan la respuesta de los bienaventurados a la oración de Beatriz representan el reconocimiento del límite cognitivo de la inteligencia humana en presencia de una verdad divina que no es cognoscible por completo. El poeta narra que las luces de los bienaventurados comenzaron a girar formando círculos con un centro fijo, similares a los engranajes del reloj que giran más o menos rápido: del círculo que a Dante le pareció más bello, salió San Pedro, una luz que brilló más que todas las demás y que giró tres veces en torno a Beatriz, cantando un canto tan celestial que el viator no pudo describirla ${ }^{8}$.

Pero salta la pluma y no lo escribo, / que nuestra imaginación en tales pliegues / no sólo el habla, excede de color vivo.
La pluma del poeta omite esta parte del Paraíso porque nuestra imaginación y nuestro lenguaje son insuficientes para poder describirla con todas sus matices. El límite insuperable de la imaginación y del lenguaje humano no permite utilizar los "colores adecuados" para representar cosas tan elevadas.

Beatriz, al retomar la palabra, ruega a San Pedro, a quien Cristo confió las llaves del Paraíso, que examine a Dante sobre la virtud de la fe. El primero de los Apóstoles ya sabe que el poeta posee esa virtud, pero Beatriz destaca que es necesario que el viator enfrente dicho examen para que la fe sea glorificada por su testimonio. Además, algunos dantistas destacan que Dante necesita proclamar la sinceridad de su fe para continuar su camino ${ }^{10}$. La fe terminará, como dice el apóstol Pablo en la Primera Carta a los Corintios, cuando veamos a Dios 'cara a cara'11. Al final de su camino, Dante podrá contemplar la luz eterna. Sin embargo, como subrayan otros dantistas, la fe es una virtud teológica que no está esencialmente vinculada al Paraíso, sino a la Tierra. '¿Alguien me preguntará [en el Paraíso]: ¿crees? No, de hecho'12, contesta Guillermo de Saint Thierry. Después de todo, Dante dice expresamente que está viendo algunos misterios divinos que a los ojos de los mortales en la Tierra son tan inaccesibles que su existencia es solo un acto de fe. Está escrito en el canto XXIV del Paraíso:

Las profundas cosas / que me alargan aquí su presencia, / a los ojos de allá abajo están tan escondidas, / que su existencia está en la sola creencia ${ }^{13}$.

El examen sobre la virtud de la fe no tiene que ver solamente con su camino paradisíaco hacia la contemplación de la luz eterna, sino también con la misión que todavía él debe cumplir en la Tierra. El viator ve que los hombres que viven "allá abajo" están perdiendo la fe, alejándose de su salvación ${ }^{14}$. El poeta recuerda que 'la planta buena' ${ }^{15}$ que sembró en

1. Los cantos XXIV, XXV y XXVI del Paraíso constituyen una secuencia textual unitaria en la cual Dante prueba su posesión de las tres virtudes teologales. En el canto XXV, Dante responderá a las preguntas de los Apóstoles Santiago (sobre la esperanza) y Juan (sobre la caridad). El triple examen prepara a Dante para la ascensión a los siguientes Cielos, el Primo Móvil y el Empíreo. Sobre la estructura unitaria de estos tres cantos, véase Scrivano 1996.

2. Paraíso, XXIV, 2-3. Los versos del canto XXIV citados en el presente artículo han sido traducido por Juan José Sanguineti.

3. Paraíso, XXIV, 9.

4. Dante escribe: 'si por gracia de Dios éste preliba / de lo que cae de vuestra mesa'. Paraíso, XXIV, 4-5.

5. 'Y ella dijo: Sí, Señor; pero aun los perrillos comen de las migajas que caen de la mesa de sus amos'. Evangelio según Mateo, 15:27.

6. La metáfora de la comida, acogida por la Patrística, ha tenido gran importancia en la cultura cristiana. Véase Curtis, 1995, pp. 154-156.

7. El deseo ilimitado de Dante y su sed inextinguible, sólo se saciará en el Empíreo donde le aparecerán los nueve coros angelicales y la "rosa blanca" de los bienaventurados, preludio de la visión de Dios que concluirá el viaje en el más allá

8. Véase Paraíso, XXIV, 13-24. En cuanto a la verdad divina y a la dificultad de describirla, Domenico Cofano ha hablado de la unidad absoluta de la hipersignificación divina. Véase Cofano 2002.

9. Paraíso, XXIV, 25-27.

10. Véase Benfell 1997, p. 95; Pellegrini 2019, p. 75.

11. Primera carta a los Corintios, 13-12.

12. William of Saint Thierry 1979, pp. 3-4. Los pasajes de los volúmenes que no son publicados en español han sido traducidos por mí.

13. Paraíso, XXIV, 70-73.

14. La fe y la teología excluyen un enfoque puramente contemplativo, porque la revelación divina se configura como la "verdad que salva", lo que obliga a considerar siempre su aspecto pragmático. En cuanto a la teología, Étienne Gilson destaca que el mismo rigor epistémico de un conocimiento no depende de los fines para el que fue elaborado. Véase Gilson 1953. Antonio Livi escribe: 'El carácter científico de la teología, en definitiva, no sólo no excluye sino que implica que esta dimensión eminentemente "práctica" esté siempre operativa, como conocimiento orientado a una comprensión cada vez mejor, a través del estudio de la verdad revelada, lo que es necesario creer (quid sit credendum) y cómo es necesario vivir (quid sit faciendum) para obtener la salvación'. Livi 2017, pp. 71-72.

15. Paraíso, XXIV, 110. 
la pobreza el primero de los Apóstoles (el que se hizo heraldo de la fe) 'ahora se ha hecho espino' ${ }^{16}$. Mirando a la difícil situación eclesiástica de su tiempo, Dante asume el papel teológico-eclesial de proteger y transmitir la Palabra de Dios con el fin de restaurar la unidad perdida de la Iglesia militante ${ }^{17}$.

La fe misma debe ser testificada con obras, pero también predicada con palabras. Dante, a la hora de hablar de la virtud de la fe, recurre abundantemente a la terminología escolástica. De hecho, el examen se realiza sobre la base de los más rigurosos términos filosóficos y según las convenciones típicas de la educación superior de la época. El mismo poeta se siente como el bachiller, o sea como el alumno que debe rendir el examen final de un curso de teología, y prepara los argumentos para la discusión sin hablar hasta que el profesor haya propuesto la cuestión a resolver ${ }^{18}$. También nótese que San Pedro plantea la primera pregunta utilizando los términos técnicos propios de las quaestiones disputatae en los estatutos universitarios medievales: '¿qué es la fe?'19 ("quid est fides"). Ahora bien, el viator, al contestar a dicha pregunta, repite textualmente la definición paulina contenida en el Carta a los Hebreos ${ }^{20}$ :

Fe es sustancia de las cosas esperadas, / y argumento de las que no aparecen; / y esta es la que me parece su quiddidad ${ }^{21}$.
El poeta no se limita a ofrecer dicha definición, sino que tambiénmquiere dar razones de su fe. Por ello, San Pedro subraya que la respuesta es correcta, siempre y cuando Dante sepa por qué San Pablo habló de sustancia y argumento. Y Dante explica que es correcto hablar de sustancia porque sobre la fe se funda la esperanza de la beatitud, y que es correcto hablar de argumento porque a partir de la fe debemos argumentar sin recurrir a otras pruebas ${ }^{22}$. Se trata de una explicación que nos muestra que, para el poeta, la fe, aunque tenga por objeto los misterios divinos que están ocultos a los ojos de los creyentes, no está totalmente desvinculada de la razón. La creencia, aunque requiera de un acto supremo de voluntad por la no-evidencia intrínseca de la verdad divina, sigue siendo verdadero conocimiento que, como tal, se basa en un 'motivo racional'23.

La adhesión de Dante a los misterios divinos es sólida, firmísima. Cuando se le pregunta si posee la fe, el poeta contesta que no tiene absolutamente ninguna duda sobre la fe. Tanto es así que inventa un neologismo (el verbo "s'inforsa") para subrayar que en su creencia no hay espacio para ninguna incertidumbre ${ }^{24}$. Se trata de una certeza absoluta que no proviene de argumentos humanos, sino de la inspiración

16. Paraíso, XXIV, 111. El hecho de que la comunidad de los creyentes se haya vuelto corrupta ("espino") no empuja a Dante a alejarse de la Iglesia y a profesar una fe meramente privada. El canto se cierra con una síntesis de la profesión de fe basa en el Credo. ' $Y$ creo en tres personas eternas, y ellas creo ser una esencia tan una y tan trina, que a la vez admitieran son y es'. Paraíso XXIV 139-41. Nótese que esta síntesis sigue la fórmula oficial de la doctrina. El viator se reconocen como miembro de la Iglesia de Cristo, que es una, precisamente en virtud del asentimiento de cada fiel a esas mismas verdades que constituyen "una fides". Desde este punto de vista, hay que distinguir entre la autoridad meramente humana de los creyentes que forman parte de la comunidad cristiana y la autoridad sobrenatural de la Esposa Mística de Cristo, es decir, la indefectibilidad y la santidad de la Iglesia en la historia de la salvación.

17. La misión del poeta en la Tierra se puede vincular con la conclusión del canto en el cual San Pedr bendice a Dante, exactamente como lo hizo con Beatriz al comienzo. Baranski escribe: 'Es conviene que sea San Pedro, jefe del "primer convento", ganador de la carrera de la fe [...], quien consagre a Dante-personaje en su nuevo papel de "sembrar la planta buena" (110). El apóstol aprueba repetidamente lo que afirma el viator [...] Dante, a diferencia de sus pastores descarriados y rapaces, es alguien en quien otros pueden confiar: gracias a él pueden reavivar en sí mismos la "chispa" (145) de la fe y aprender los principios de la fe (130-144). [...] Él también, cuando esté en el exilio, será "pobre y ayuno" (109); él también asumirá una posición de liderazgo espiritual; él también es un scriba Dei'. Baranski, 2021, p. 504.

18. Dante escribe: 'Así como el bachiller se arma y no habla, / hasta que el maestro la cuestión propone, / para aprobarla, no por terminarla, / así me armaba yo de toda razón, / mientras ella hablaba, para estar dispuesto / a tal cuestor, y a tal profesió'. Paraíso, XXIV, 46-51. Por lo que se refiere a la relación entre el bachiller y el profesor y a los procedimientos típicos de las universidades medievales, véase Waters 2015, pp. 19-60 y Imbach 2019.

19. Paraíso, XXIV, 53.

20. Carta a los Hebreos, 53-66

21. Paraíso, XXIV, 64-66.

22. Véase Paraíso, XXIV, 65-78.

23. Casali 1956 p. 109. A propósito de la fe, Tomás de Aquino sostiene: 'El de la fe es un acto del entendimiento que asiente a la verdad divina bajo el imperio de la voluntad movida por la gracia de Dios; se trata, pues, de un acto sometido al libre albedrío y es referido a Dios'. Tomás de Aquino, Suma teológica, II-II, q. 2, a. 9. Tomás de Aquino, al hablar del asentimiento del intelecto, sigue Agustín, según el que 'el mismo acto de fe no es otra cosa que el pensar con el asentimiento'. Agustín, La predestinación de los Santos, 2, 5. Javier María Prades López describe acertadamente: 'La teología siempre ha tenido la pretensión de concebir el mensaje cristiano en términos no irracionales o voluntaristas, y siempre ha sentido la necesidad de dar razón de su esperanza [cfr. 1Pt 3,15]'. Prades-López 2008, p. 13). La tesis de que en el acto de fe el contenido depende de la voluntad, no lleva a Dante a acoger ninguna postura fideística.

24. Dante recurre a la metáfora de la moneda preciosa para expresar su certeza de fe: 'Asaz bien apreciada / de la moneda la liga fue y el peso; / mas dime si la tienes en tu bolsa. / Y yo: Sí, la tengo, tan lúcida y redonda, /que de su cuño no hay duda ninguna'. Paraíso, 83-87. La respuesta del poeta a la pregunta de San Pedro está perfectamente en línea con la enseñanza de Cristo, el cual pretende que el fiel crea 'sin vacilar en su interior'. Evangelio según Marcos, 11, 23. 
del Espíritu Santo que iluminó el Antiguo y el Nuevo Testamento ${ }^{25}$. Es la Gracia la que permite al fiel adherir a las verdades divinas sin albergar ninguna duda. A este respecto, cabe señalar que el viator distingue claramente entre la incuestionabilidad de la fe sobrenatural y la duda de la investigación científica. En comparación con la firmeza de la fe sobrenatural, dice Dante, 'toda demostración parece obtusa'26. En todo caso, la inspiración interior de Dios no puede representar una explicación exhaustiva de la certeza de la fe cristiana. En efecto, el viator se ve obligado a contestar a otras dos preguntas. Está escrito en el canto XXIV del Paraíso:

La antigua y la nueva / proposición que así para ti concluye, / ¿por qué la piensas divina elocuencia? ${ }^{27}$.

El viator contesta que la prueba de esta inspiración interior está constituida por los milagros que narran las Escrituras, milagros que no se pueden explicar con argumentos naturales ${ }^{28}$. Estamos frente a una respuesta que muestra muy bien la estructura lógica que pertenece a la fe. Es posible adherir a la verdad que salva sin ninguna indecisión en virtud del papel epistemológico que desarrolla la autoridad de los demás en el mismo acto de $\mathrm{fe}^{29}$. Dicho de otro modo, el conocimiento de los misterios divinos pasa a través del conocimiento que el fiel adquiere de la fiabilidad de los testigos cristianos que es reconocible por los hechos que han realizado, fiabilidad que ofrece un motivo para creer (creer que implica, en todo caso, el imperio de la voluntad movida por la Gracia, dada la no-evidencia de la verdad sobrenatural). Además, leemos en el canto XXIV del Paraíso:

Di ¿quién te asegura / que existieron las obras? Aquello mismo / que quiere probarse, no otro, te lo jura ${ }^{30}$.

El autor de la Divina Comedia ofrece una ulterior aclaración lógica de la fe mediante la objeción de San Pedro, según la cual no podemos saber con certeza que esos milagros realmente ocurrieron, ya que solo los atestiguan las Escrituras. Sostener que la autenticidad divina de las Escrituras puede ser garantizada por las Escrituras mismas constituye un 'círculo vicioso' 31 , lo que los estudios de lógica definen como una petitio principii, que es la falacia que se produce cuando lo que se quiere probar ya está incluido implícita o explícitamente entre las premisas de una demostración. De ahí la necesidad de otra respuesta:

Si el mundo volvióse al cristianismo, / dije yo, sin milagros, es que él es uno / tal, que los demás un céntimo no valen ${ }^{32}$.

25. La fe requiere de la ayuda de la Gracia, porque es un acto sobrenatural, un regalo que el hombre recibe por el influjo de una luz infusa. Desde este punto de vista, cabe señalar que la persona que se encomienda al testimonio de otros hombres debe seguir temiendo que sea verdadero el contrario de lo que está testimoniado; en cambio, la persona que se encomienda al testimonio divino puede estar segura de la verdad del mensaje comunicado. Enrico Berti escribe: 'La fe no es un saber, es decir, no satisface el natural deseo de saber, está expuesta a la duda, es una situación de inquietud, requiere un continuo ejercicio de renuncia a la comprensión y la confianza en los demás; en fin, es una virtud, aunque "teologal", es decir, una virtud que requiere la cooperación de la gracia divina'. Berti 2009, p. 53. En cuanto a la Gracia de la que habla Dante, Sebastiano Valerio escribe: 'La Gracia del Espíritu Santo, que dio a los apóstoles el lenguaje para hablar de Cristo, iluminó las Escrituras con la misma abundancia de bien que Dante había pedido que se le concediera para poder responder correctamente al examen de Pedro'. Valerio 2008, p. 337.

26. Paraíso, XXIV, 96.

27. Paraíso, XXIV, 97-99.

28. El poeta escribe: 'Y yo: La prueba que mi visión despeja / son las obras siguientes, pues la natura / no calienta nunca hierro ni bate yunque'. Paraíso, XXIV, 100-102.

29. Con relación al conocimiento que se adquiere por medio de un testimonio, Józef M. Bochenski habla de autoridad epistemológica del testigo. Véase Bochenski 1979, p. 70. Por otra parte, la postura del poeta está perfectamente en línea con la enseñanza magistral de hoy. En el Catecismo de la lglesia católica, §177, está escrito: "Creer" entraña, pues, una doble referencia: a la persona y a la verdad; a la verdad por confianza en la persona que la atestigua'. Es un pasaje al cual recurre Francisco Conesa, el que - siguiendo las huellas de algunos autores como Henry Price y James Kellenberger subraya: 'La fe en verdades, en "algo" no está aislada y sin relación con la persona creída, sino que más bien es ésta el soporte de los enunciados. La aceptación de cualquier contenido de la fe depende de la aceptación de Dios mismo, de la adhesión a él'. Conesa 1994, p. 485. Véase Price 1964, p. 9 y Kellenberger 1980, pp. 27-39.

30. Paraíso, XXIV, 103-105.

31. Nardi 1990, p. 170.

32. Paraíso, XXIV, 106-108. En el canto XXIV está escrito también: 'Porque tú entraste pobre y ayuno / en el campo, a sembrar la planta buena, / que fue ya viña, y ahora se ha hecho espino'. Paraíso, XXIV, 109-111. Es un milagro la misma predicación del San Pedro, quien en la pobreza puso los cimientos del edificio de la Iglesia. A propósito de la vinculación entre las Escrituras y la Iglesia, destaca Antonio Livi: 'es la Iglesia, de hecho, la que establece el "canon" de los libros inspirados y es ella la que los interpreta como un auténtico documento de revelación divina. Este es un principio fundamental de la fe católica, reafirmado solemnemente por el Concilio Vaticano II'. Livi 2017, pp. 105-106. 
Dante recurre al argumento de Agustín de que la difusión del cristianismo en el mundo es "en sí mismo" un milagro capaz de demostrar la veracidad de los textos sagrados ${ }^{33}$. Es 'la realidad viva del cristianismo, que había transformado el mundo pagano', como señala Bruno Nardi, 'la que constituye para Agustín, como para Dante, el milagro de los milagros' ${ }^{34}$.

Quisiera detenerme en la concepción de Dante sobre la relación entre la fe y la ciencia teológica. Si bien en la Divina Comedia no se encuentra la palabra "teología", se puede entender cuál es la postura del poeta sobre este tema, comparando algunos versos del canto XXIV con la noción medieval de dicha disciplina. A este respecto, hay que decir que la distinción anteriormente señalada entre la incuestionabilidad de la fe sobrenatural y la duda de la investigación científica no debe empujarnos a pensar que el poeta concibe dicha distinción en términos de antítesis. El hecho de que la certeza absoluta de la fe no sea 'fruto de la reflexión racional, sino consecuencia de la Gracia' ${ }^{35}$ es compatible con 'los cánones de la doctrina escolástica considerados, a su vez, con sus procedimientos dialécticos y didácticos ${ }^{\prime 36}$. Es cierto que para Dante la fuente de la fe cristiana no es el razonamiento humano imperfecto y defectuoso, sino la inspiración interna y personal de Dios $^{37}$, pero es cierto también que lo que sostiene el poeta puede verse como un rechazo de la teología solo si se desconoce o se mal entiende el estatuto epistemológico que los escolásticos, en particular Tomás de Aquino, confieren a la ciencia de la fe. En cuanto a la teología, el Aquinate sostiene de manera explícita:

Este conocimiento no lo podemos tener perfectamente en esta vida, pero sí es posible una cierta participación y asimilación al conocimiento divino, en cuanto que por la fe infusa en nosotros nos adherimos a la verdad primera por sí misma. [...] Así pues, las verdades que adquirimos por la fe son como los principios de esta ciencia, y lo demás, como las conclusiones ${ }^{38}$.

Lo que creemos por la fe infusa por la Gracia divina constituye el punto de partida o la condición de posibilidad de la ciencia teológica. La teología propiamente dicha es esa 'doctrina argumentativa' ${ }^{39}$ que, a partir de las verdades de fe, llega a demostrar otras verdades ${ }^{40}$. La creencia personal en Dios y la ciencia de la fe pertenecen a dos niveles cognitivos diversos y difieren en cuanto a su justificación epistémica.

33. Nótese que esta respuesta de Dante no es una negación de la estructura lógica anteriormente señalada, sino más bien una ulterior especificación suya, en la medida en que reconduce la prueba del milagro a la "realidad viva" de los testigos y a la fiabilidad de la Iglesia.

34. Nardi 1990, p. 171. En la misma página Nardi escribe también: 'La fe no es otra cosa que el reconocimiento de la fuerza activa de doctrina cristiana en la realidad viva de la historia'. Con su respuesta Dante reconoce que la religión cristiana no es a sí misma una religión del Libro, sino principalmente una religión de la Palabra de Dios que 'se transmite en la Tradición viva de la Iglesia'. Benedicto XVI, Verbum Domini, Exhortación apostólica postsinodal, 30 de septiembre 2010, n. 7. En efecto, Cristo ordenó a los apóstoles que predicaran el Evangelio, no que lo relegaran a las Escrituras. Véase Beumer 1967, p. 163.

35. Baranski 2021, p. 513. Este estudioso sostiene que la 'tradición interpretativa que ha considerado "este canto" como "reductivamente didáctico e intelectualista" [...] va en contra de la poderosa y repetida declaración sobre la fe del personaje-Dante como divinamente inspirada, afectiva y personal'. Ibidem, 497. La expresión "reductivamente didáctico e intelectualista" se encuentra en Battistini 2016, p. 280. Baranski hace referencia también, entre otros, a D'Elia 2017, p. 354.

36. Di Gregorio 2000, p. 469. Dante, mientras se prepara para enfrentar el examen, pide a la Gracia que pueda expresar bien sus conceptos frente al fundador de la Iglesia. Véase Paraíso, XXIV, 79-80. Invocar la ayuda de la Gracia de Dios es una acción típica del teólogo. Por ejemplo, Tomás de Aquino, al comienzo de la Suma teológica, escribe: 'Confiando en la ayuda de Dios, intentaremos poner remedio a todos esos inconvenientes presentando de forma breve y clara, si el problema a tratar lo permite, todo lo referente a la doctrina sagrada'. Tomás de Aquino, Suma teológica, Prólogo. El teólogo que está a punto de dar razones de la fe, ante todo debe prepararse con la oración para que, con la ayuda de la Gracia divina, pueda desarrollar sus razonamientos. En este sentido, se pueden interpretar también las palabras de San Pedro cuando, dirigiéndose al viator, le dice que la Gracia le ha sugerido como abrir la boca. Véase Paraíso, XXIV, 118-120. A la luz de lo dicho, se puede sostener que es incorrecto recurrir a las parabas de San Pedro recién mencionadas - como hace Baranski - para sostener la incompatibilidad entre la argumentación racional del teólogo escolástico y el discurso de Dante. Véase Baranski 2021, p. 513.

37. Valerio dice: «La posibilidad de definir verdaderamente la fe, sin embargo, no podía separarse [...] de una profunda interiorización de lo que había sido el alimento del alma y el objeto de estudio». Valerio 2008, p. 332.

38. Tomás de Aquino, Comentario al De Trinitate de Severino Boecio, cuestión 2, artículo 2. En cuanto a la fe entendida como punto de partida o condición de posibilidad de la ciencia teológica, el Aquinate menciona no solo la fe infusa en nosotros, sino también la fe revelada por medio de los testigos cristianos. En el Comentario al De Trinitate, q. 2, a. 2, ad. 4, está escrito: 'En efecto, las verdades que, en la ciencia que Dios tiene de sí mismo, son conocidas por sí mismas, en nuestra ciencia se ponen como fundamento, pues creemos a Dios, que nos revela esas cosas por medio de sus enviados'. Desde este punto de vista, cabe señalar que non es correcto recurrir a la 'circularidad' de la 'argumentación racional' del que habla Dante para sostener la tesis de que el poeta, a la hora de hablar de la fe, devalúa 'las "pruebas" generadas racionalmente'. Baranski 2021, p. 513. Dante no usa el problema del círculo vicioso para negar toda argumentación racional, sino - como hemos visto - para reconducir la prueba del milagro a la realidad viva los testigos de Dios, o - como dice Tomás de Aquino en el pasaje recién citado - a 'sus enviados'. En resumen, no hay contradicción entre la postura de Dante y la del máximo representante de la doctrina escolástica.

39. Tomás de Aquino, Suma Teológica, I, 1, 8, c.

40. Tomás de Aquino sostiene: 'Así como las otras ciencias no argumentan para probar sus principios, sino que, partiendo de tales principios, argumentan para demostrar otras cosas que hay en ellas, de la misma forma la doctrina sagrada no argumenta para probar sus principios, los artículos de fe, sino que, a partir de ellos, argumenta para probar otra cosa. Por ejemplo, el Apóstol en 1 Cor 15,12ss, partiendo de la resurrección de Cristo, argumenta para probar la resurrección de la humanidad'. Tomás de Aquino, Suma Teológica, I, q. 1, a. 8. 
La primera se justifica por la inspiración interior, la segunda encuentra su justificación en un método capaz de reconducir sus conclusiones a lo que ya se cree. Por lo tanto, no hay ninguna incompatibilidad entre la fe sólida e indudable de Dante y los procedimientos dialécticos desarrollados por los escolásticos. Desde este punto de vista, cabe señalar que los teólogos medievales, en cuanto científicos, retoman los criterios epistemológicos de Aristóteles, según los cuales las premisas deben ser "más conocidas" que las conclusiones. La certeza de la fe es "mayor" que la certeza que se puede adquirir por medio de una tesis teológica. La segunda es absoluta, la segunda es relativa. Antonio Livi, estudioso de Tomás de Aquino, escribe acertadamente:

La teología se limita a ofrecer a los creyentes hipótesis de interpretación cuya plausibilidad depende del grado de autoridad científica (calidad puramente humana) que los teólogos en su individualidad o sus instituciones y escuelas puedan merecer a los ojos de los fieles ${ }^{41}$.

Las tesis teológicas deben ser sometidas a la crítica de la comunidad científica, en cuanto requieren solamente una fe humana. El teólogo, por principio, puede equivocarse; por principio, sus conclusiones son cuestionables. En ese sentido, se puede entender la razón por la cual Dante afirma que 'las demostraciones establecidas silogísticamente son "obtusas" en comparación con las "agudeza" del Antiguo y Nuevo Testamento'42. Cuando San Pedro, aprobando las palabras del viator, dice que 'no tendría espacio el ingenio del sofista'43 si todo lo que se aprende en la Tierra fuese entendido de la misma manera ${ }^{44}$, no quiere refutar los argumentos humanos en cuanto tales, sino solo sus distorsiones. De lo contrario, no tendría sentido armarse 'de toda razón'45, como dice Dante antes de contestar a las preguntas de San Pedro.
El método teológico de Tomás de Aquino según el cual la teología debe partir de las verdades de fe para llega a demostrar otras verdades, es un procedimiento científico aceptado por Dante, el cual dice en el canto XXIV:

Y de esta creencia es necesario / silogizar, sin buscar otra salida; / porque valor de argumento tiene ${ }^{46}$.

Con la expresión "sin buscar otra salida" Dante no quiere contraponer la creencia cristiana con la demostración escolástica, sino indicar el camino que el teólogo debe recorrer para demostrar sus tesis. Los versos citados presuponen implícitamente la distinción epistemológica entre teología y filosofía ${ }^{47}$. A este respecto, se puede admitir que implícitamente el poeta acepta la epistemología tomista. El Aquinate expresa:

Hay una doble ciencia de lo divino. Una, según nuestro modo de conocer: toma sus principios de lo sensible para dar a conocer las realidades divinas. Los filósofos construyeron de ese modo la ciencia acerca de Dios, llamando ciencia divina a la filosofía primera. Y otra, según el modo propio de lo divino, es decir: aprehendiendo las cosas divinas en sí mismas ${ }^{48}$.

Es un error sostener que los escolásticos usan 'procedimientos racionalistas' 49 y por consiguiente considerar el canto XXIV como 'reductivamente [...] intelectualista'50. La teóloga no tiene la pretensión de racionalizar la $\mathrm{fe}^{51}$. El teólogo escolástico no quiere demostrar la verdad sobrenatural, ni tiene como objetivo hacer más comprensible,

41. Livi 2017, p. 80. También escribe Livi: 'Las opiniones exegéticas de los expertos no requieren y merecen solo un consentimiento hipotético sobre la base de la fe humana, que pertenece a cualquier teoría científica'. Ibidem, p. 114.

42. Baranski 2021, p. 513.

43. Paraíso, XXIV, 81.

44. Paraíso, XXIV, 79-80.

45. Paraíso, XXIV, 49.

46. Paraíso, XXIV, 76-78.

47. La distinción entre teología y filosofía explica por qué en el canto XXIV no hay ninguna referencia a Aristóteles o a otros filósofos.

48. Tomás de Aquino, Comentario al De Trinitate de Severino Boecio, cuestión 2, artículo 2.

49. Baranski 2021, p. 513.

50. Battistini 2016, p. 280.

51. Dante parece tomar distancia de una determinada filosofía, como la de algunos maestros parisinos, que tienen la pretensión de conocer perfectamente el objeto de la fe. En todo caso, el racionalismo propiamente dicho nació con Descartes. Este racionalismo indudablemente influyó directamente en el enfoque teológico del cristianismo en la era moderna. En este sentido, en el siglo XIX Antonio Rosmini habló de "racionalismo teológico". Véase Rosmini 1992. Hay que evitar usar esta categoría moderna para interpretar la teología medieval. 
inteligible, una verdad de fe "en sí misma", reduciéndola a categorías análogas a las que elabora la filosofía para entender la realidad. De no ser así, los teólogos conocerían mejor los misterios divinos, creyendo más que todos los demás creyentes que no son teólogos ${ }^{52}$. También en la teología de Tomás de Aquino los misterios siguen siendo verdades intrínsecamente no evidentes ${ }^{53}$. La teología solamente puede hacer más comprensible, inteligible, una verdad de fe "en relación" al determinado contexto socio-cultural en el cual se encuentra el fiel. En este sentido el teólogo no propone nuevas verdades de fe, sino interpretaciones de los misterios 'con conceptos (en el caso de una teología dogmática) y reglas de conducta personal y social (en el caso de una teología moral), o con imágenes (en el caso del arte sacro y la literatura de inspiración religiosa $)^{\prime 54}$. Un ejemplo resplandeciente de literatura de inspiración religiosa es sin duda la poesía de Dante ${ }^{55}$.

52. En este sentido, cabe señalar que la tesis de que el fiel 'no se necesita [...] ser teólogo para apreciar la fe "agudamente"' (Bara冈ski 2021, p. 513) no puede ser un motivo para sostener que Dante refuta los cánones de la doctrina escolástica.

53. La Gracia no hace que el objeto de fe se vuelva evidente. El concepto mismo de la fe requiere la oscuridad del objeto.

54. Livi 2017, p. 75.

55. Por un lado, Dante no niega la doctrina argumentativa de la escolástica, por otro su forma de tratar los temas teológicos está constituida por el lenguaje simbólico propio de la poesía. Como dice Valerio, Dante escribe no solo en un estilo bello, sino también en un estilo verdadero. Véase Valerio 2008, pp, 337-338. Además, dice Livi: 'En resumen, la teología no puede practicarse como si su propósito fuera la crítica a la fe (la razón humana nunca tendrá ninguna razón real para negar la verdad revelada) ni como si su tarea fuera producir nuevas verdades para creer. En cambio, el propósito y la tarea de la teología es "vivir" y hacer "vivir" la fe por la cultura de cada tiempo y lugar, con resultados que a veces tienen el valor y la función de riquezas de la fe durante muchos siglos y para muchos lugares diferentes, como ocurrió con Agustín y Tomás de Aquino, pero también, en lo que respecta a las interpretaciones literarias, con Dante Alighieri'. Livi 2017, p. 74. 


\section{BIBLIOGRAFÍA}

- Baranski G., Zygmunt, "'lo credo. . .': 'Professing' faith in Paradiso 24”, en Forum Italicum, 2 (2021), pp. $496-523$.

- Battistini, Andrea, Fede e bellezza. Il tessuto metaforico del canto XXIV del Paradiso, en id., La retorica della salvezza. Studi danteschi, Bologna, il Mulino, 2016, pp. 271-289.

- Benfell, V. Stanley, "Biblical truth in the examination cantos of Dante's Paradiso", en Dante Studies, 115 (1997), pp. 89-109.

- Berti, Enrico A quali condizioni una fede può avanzare una pretesa di ragionevolezza?, en V. Possenti (ed.), Ritorno della religione? Tra ragione, fede e società, Milano, Guerrini e Associati, 2009, pp. 52-57.

- Beumer, Johannes, La tradition orale. Histoire des Dogmes, Paris, Cerf, 1967.

- Bochenski, Józef M., ¿Qué es autoridad?, Barcelona , Editorial Herder, 1979.

- Casali, Giuseppe, Somma di Teologia Dogmatica, Lucca, Edizioni Regnum Christi, 1956.

- Cofano, Domenico, La retorica del silenzio nella 'Divina Commedia', Bari, Palomar, 2002.

- Conesa, Francisco, "La fe y la lógica del testimonio", en Scripta Theologica, 26/2 (1994), pp. 483-512.

- Curtis, Ernst Robert, Letteratura europea e Medio Evo latino, ed. R. Antonelli, Firenze, La Nuova Italia, 1995.

- D’Elia, Antonio, “Dante e la buona battaglia: Il canto XXIV del Paradiso”, en Letteratura italiana antica, 18 (2017), pp. 353-375.

- Di Gregorio, Francesco, Canto XXIV, en P. Giannantonio (ed.), Lectura Dantis Neapolitana. Vol 3. Paradiso, Napoli, Loffredo, 2000, pp. 457-484.

- Gilson, Étienne “Les maîtresses positions de Duns Scot d'après le Prologue de I'Ordinatio", en Antonianum, 28 (1953), pp. 7-18.

- Imbach, Ruedi, Dante come allievo e maestro, en id., Minima mediaevalia. Saggi di filosofia medievale, Caterano, Aracne, 2019, pp. 197217.

- Kellenberger, James, "Faith and Emotion", en Sophia, 19/3 (1980), pp. 31-43.

- Livi, Antonio, Vera e falsa teología, Come distinguere I'autentica 'scienza della fede' da un'equivoca 'filosofia religiosa', Roma, Casa Editrice Leonardo da Vinci, 2017.

- Nardi, Bruno, Dante e la cultura medievale, Bari, Laterza, 1990.

- Prades-López, Javier María, “Il Cristianesimo e la necessità del testimone”, en Oasis, 7 (2008), pp. 12-16.

- Pellegrini, Angelo, "Che soffera congiunto 'sono' ed 'este'. La professione di fede trinitaria di Dante Alighieri nel Paradiso e i precedenti su Dio trino in Inferno e Purgatorio", en Vivens homo, 30 (2019), pp. 71-99.

- Price, Henry H. Faith and Belief, en J. Hick (ed.), Faith and the Philosophers, New York, St. Martin's Press, 1964, pp. 3-37.

- Rosmini, Antonio, Il razionalismo teologico, ed. G. Lorizio, Roma - Stresa, Città Nuova, 1992.

- Scrivano, Riccardo, Tramature bibliche del Paradiso. I canti dell'esame, en E. Esposito, et al. (eds.), Memoria biblica nell'opera di Dante, Roma, Bulzoni, 1996, pp. 99-119.

- Valerio, Sebastiano, Dante 'a la gran cena' (Par. XXXIV), en D. Cofano, S. Valerio (eds.), Versi controversi, Letture dantesche, Foggia, Edizioni del Rosone, 2008, pp. 319-344.

- Waters, Claire M., Translating Clergie: Status, Education, and Salvation in Thirteenth-Century Vernacular Texts, Philadelphia, University of Pennsylvania Press, 2015.

- William of Saint Thierry, The Mirror of Faith, Kalamazoo, Cistercian Publications, 1979. 